Pacific Journal of Mathematic 


\section{FIXED POINT ITERATIONS OF NONEXPANSIVE MAPPINGS}

\section{SIMEON REICH}

Let $C$ be a boundedly weakly compact convex subset of a Banach space $E$. Suppose that each weakly compact convex subset of $C$ possesses the fixed point property for nonexpansive mappings, and let $T: C \rightarrow C$ be nonexpansive. In this note it is shown (by a very simple argument) that if a sequence of iterates of $T$ (generated with the aid of an infinite, lower triangular, regular row-stochastic matrix) is bounded, then $T$ has a fixed point.

Dotson and Mann [3] proved this theorem under the additional assumption that $E$ was uniformly convex. (Their complicated proof relied heavily on the uniform convexity of $E$.) We use our method also to establish a similar result (essentially due to Browder) for nonlinear nonexpansive semigroups.

Let $C$ be a closed convex subset of a Banach space $(E, \mid)$, and let $T: C \rightarrow C$ be nonexpansive (that is, $|T x-T y| \leqq|x-y|$ for all $x$ and $y$ in $C$ ). Let $N$ denote the set of nonnegative integers, and suppose $A=\left\{a_{n k}: n, k \in N\right\}$ is an infinite matrix satisfying

$$
\begin{aligned}
a_{n k} & \geqq 0 \quad \text { for all } n, k \in N, \\
a_{n k}=0 & \text { if } k>n, \\
\sum_{k=0}^{n} a_{n k}=1 & \text { for all } n \in N, \\
\lim _{n \rightarrow \infty} a_{n k}=0 & \text { for all } k \in N .
\end{aligned}
$$

If $x_{0}$ belongs to $C$, then a sequence $S=\left\{x_{n}: n \in N\right\} \subset C$ can be defined inductively by

$$
x_{n}=a_{n 0} x_{0}+\sum_{k=1}^{n} a_{n k} T x_{k-1}, \quad n \in N \text {. }
$$

This iteration scheme is due to Mann [8].

It is not difficult to see that if $T$ has a fixed point, then $S$ is bounded. Dotson and Mann [3, Theorem 1] have proved that if $E$ is uniformly convex, and if $S$ is bounded for some $x_{0}$ in $C$, then $T$ has a 
fixed point. Their proof is rather complicated and relies heavily on the uniform convexity of $E$. In this note we establish a far-reaching extension of the Dotson-Mann theorem in a very simple manner. We remark in passing that a special case of the Dotson-Mann result was independently established by Reinermann [10, p. 10]. He assumed that $A$ is column-finite.

THEOREM 1. Let $C$ be a boundedly weakly compact convex subset of a Banach space E. Suppose that each weakly compact convex subset of $C$ possesses the fixed point property for nonexpansive mappings, and that $T: C \rightarrow C$ is nonexpansive. If the sequence $S$ defined above is bounded for some $x_{0}$ in $C$, then $T$ has a fixed point.

Proof. Pick a point $y$ in $C$, and set $R=\lim \sup _{n \rightarrow \infty}\left|y-x_{n}\right| . \quad R$ is finite because $S$ is bounded. Let $K=\left\{z \in C: \lim \sup _{n \rightarrow \infty}\left|z-x_{n}\right| \leqq R\right\}$. $K$ is a non-empty bounded closed convex (hence weakly compact) subset of $C$. Now let $z$ be in $K$. Then

$$
\begin{aligned}
\left|T z-x_{n}\right| & \leqq a_{n 0}\left|T z-x_{0}\right|+\sum_{k=1}^{n} a_{n k}\left|T z-T x_{k-1}\right| \\
& \leqq a_{n 0}\left|T z-x_{0}\right|+\sum_{k=1}^{n} a_{n k}\left|z-x_{k-1}\right|
\end{aligned}
$$

For each positive $\epsilon$, there is $m(\epsilon) \in N$ such that $\left|z-x_{k}\right|<R+\epsilon$ for all $k>m$. Therefore we obtain for $n>m+1$,

$$
\begin{aligned}
\left|T z-x_{n}\right| & \leqq a_{n 0}\left|T z-x_{0}\right|+\sum_{k=1}^{m+1} a_{n k}\left|z-x_{k-1}\right|+\sum_{k=m+2}^{n} a_{n k}(R+\epsilon) \\
& \leqq a_{n 0}\left|T z-x_{0}\right|+\sum_{k=1}^{m+1} a_{n k}\left|z-x_{k-1}\right|+R+\epsilon \\
& =h(n)+R+\epsilon
\end{aligned}
$$

where $\lim _{n \rightarrow \infty} h(n)=0$. Thus $T z$ belongs to $K$, and the result follows.

REMARK. $S$ need not converge, even if $E$ is a Hilbert space [5].

In the setting of Theorem 1 , let $r_{m}=\inf \{r$ : there exists $y \in C$ such that $\left|y-x_{n}\right| \leqq r$ for all $\left.n \geqq m\right\}$, and $R=\lim _{n \rightarrow \infty} r_{m}$. Since $C$ is convex and boundedly weakly compact, there is at least one point $z$ in $C$ such that $\lim _{\sup _{n \rightarrow \infty}}\left|z-x_{n}\right|=R$. Such a point is called an asymptotic center of $S$ with respect to $C$ (cf. [4]). The proof of Theorem 1 shows that the set of asymptotic centers of $S$ with respect to $C$ is invariant under $T$ (cf. $[9$, p. 253]). Consequently, it contains a fixed point of $T$. In particular, if the asymptotic center is unique (this indeed happens when $E$ is 
uniformly convex, or more generally, uniformly convex in every direction [2]), then it is a fixed point of $T$. Note that a weakly compact convex subset of a Banach space which is uniformly convex in every direction has normal structure and therefore possesses the fixed point property for nonexpansive mappings [6].

The idea of the proof of Theorem 1 can be also applied to a result on nonlinear nonexpansive semigroups which is essentially due to Browder [1].

Recall that a nonexpansive semigroup on a subset $D$ of a Banach space $E$ is a function $U:[0, \infty) \times D \rightarrow D$ satisfying the following conditions:

$$
U\left(t_{1}+t_{2}, x\right)=U\left(t_{1}, U\left(t_{2}, x\right)\right) \text { for } t_{1}, t_{2} \geqq 0
$$

and $x \in D$,

$$
|U(t, x)-U(t, y)| \leqq|x-y| \text { for } t \geqq 0
$$

and $x, y \in D$,

$$
U(0, x)=x \text { for } x \in D
$$

A semigroup $U$ is called bounded if for each $x$ in $D$ there is $M(x)$ such that $|U(t, x)| \leqq M(x)$ for all $t \geqq 0$. It is said to have a fixed point $x_{0}$ if $U\left(t, x_{0}\right)=x_{0}$ for all $t \geqq 0$. If $U$ has a fixed point, then it is clearly bounded. In order to prove the converse statement, we shall assume that $D$ has the common fixed point property for nonexpansive mappings. This means that every commuting family of nonexpansive self-mappings of $D$ has a common fixed point.

THEOREM 2. Let C be a boundedly weakly compact convex subset of a Banach space E. Suppose that each weakly compact convex subset of $C$ possesses the common fixed point property for nonexpansive mappings, and that $U:[0, \infty) \times C \rightarrow C$ is a nonexpansive semigroup. If $U$ is bounded, then it has a fixed point.

Proof. Fix a point $x_{0}$ in $C$, and let $y$ be another point in $C . \quad R=$ $\lim \sup _{t \rightarrow \infty}\left|y-U\left(t, x_{0}\right)\right|$ is finite because the orbit $\left\{U\left(t, x_{0}\right): t \geqq 0\right\}$ is bounded. Let $K=\left\{z \in C\right.$ : $\left.\lim \sup _{t \rightarrow \infty}\left|z-U\left(t, x_{0}\right)\right| \leqq R\right\}$. $K$ is a nonempty bounded closed convex (hence weakly compact) subset of $C$. If $z \in K, t_{0} \geqq 0, \epsilon>0$, and $t$ is large enough, then

$$
\begin{aligned}
\left|U\left(t_{0}, z\right)-U\left(t, x_{0}\right)\right| & =\left|U\left(t_{0}, z\right)-U\left(t_{0}, U\left(t-t_{0}, x_{0}\right)\right)\right| \\
& \leqq\left|z-U\left(t-t_{0}, x_{0}\right)\right|<R+\epsilon .
\end{aligned}
$$


Consequently, $U\left(t_{0}, z\right)$ also belongs to $K$. Thus $K$ is invariant under the commuting family of nonexpansive mappings $\{U(t, \cdot): t \geqq 0\}$. Hence the result.

In the setting of Theorem 2 we can also define an asymptotic center, this time for $\left\{U\left(t, x_{0}\right): t \geqq 0\right\}$. If $E$ is uniformly convex in every direction, this asymptotic center is unique. Moreover, a weakly compact convex subset of $E$ has normal structure and therefore possesses the common fixed point property for nonexpansive mappings [7]. The proof of Theorem 2 shows that in this case the asymptotic center of $\left\{U\left(t, x_{0}\right): t \geqq 0\right\}$ is a fixed point of $U$.

REMARK. A version of Theorem 2 is true for arbitrary commutative semigroups of nonexpansive mappings.

\section{REFERENCES}

1. F. E. Browder, Nonlinear equations of evolution and nonlinear accretive operators in Banach spaces, Bull. Amer. Math. Soc., 73 (1967), 867-874.

2. M. M. Day, R. C. James and S. Swaminathan, Normed linear spaces that are uniformly convex in every direction, Canad. J. Math., 23 (1971), 1051-1059.

3. W. G. Dotson, Jr. and W. R. Mann, A generalized corollary of the Browder-Kirk fixed point theorem, Pacific J. Math., 26 (1968), 455-459.

4. M. Edelstein, The construction of an asymptotic center with a fixed point property, Bull. Amer. Math. Soc., 78 (1972), 206-208.

5. A. Genel and J. Lindenstrauss, An example concerning fixed points, to appear.

6. W. A. Kirk, A fixed point theorem for mappings which do not increase distances, Amer. Math. Monthly, 72 (1965), 1004-1006.

7. T.-C. Lim, A fixed point theorem for families of nonexpansive mappings, Pacific J. Math., 53 (1974), 487-493.

8. W. R. Mann, Mean value methods in iteration, Proc. Amer. Math. Soc., 4 (1953), 506-510.

9. S. Reich, Remarks on fixed points II, Atti Accad. Naz. Lincei Rend. Cl. Sci. Fis. Mat. Natur., 53 (1972), 250-254.

10. J. Reinermann, Approximation von Fixpunkten, Studia Math., 39 (1971), 1-15.

Received April 14, 1975.

TEL AVIV University

Current address: The University of Chicago 


\section{PACIFIC JOURNAL OF MATHEMATICS}

\section{EDITORS}

RICHARD ARENS (Managing Editor)

University of California

Los Angeles, California 90024

\author{
R. A. Beaumont \\ University of Washington \\ Seattle, Washington 98105
}

\section{J. DugundII}

Department of Mathematics

University of Southern California

Los Angeles, California 90007

D. Gilbarg and J. Milgram

Stanford University

Stanford, California 94305

\section{ASSOCIATE EDITORS}
E. F. BECKENBACH
B. H. NeumanN
F. WoLF
K. YoshidA

\section{SUPPORTING INSTITUTIONS}

\author{
UNIVERSITY OF BRITISH COLUMBIA \\ CALIFORNIA INSTITUTE OF TECHNOLOGY \\ UNIVERSITY OF CALIFORNIA \\ MONTANA STATE UNIVERSITY \\ UNIVERSITY OF NEVADA \\ NEW MEXICO STATE UNIVERSITY \\ OREGON STATE UNIVERSITY \\ UNIVERSITY OF OREGON \\ OSAKA UNIVERSITY
}

\author{
UNIVERSITY OF SOUTHERN CALIFORNIA \\ STANFORD UNIVERSITY \\ UNIVERSITY OF TOKYO \\ UNIVERSITY OF UTAH \\ WASHINGTON STATE UNIVERSITY \\ UNIVERSITY OF WASHINGTON \\ AMERICAN MATHEMATICAL SOCIETY
}

The Supporting Institutions listed above contribute to the cost of publication of this Journal, but they are not owners or publishers and have no responsibility for its contents or policies.

Mathematical papers intended for publication in the Pacific Journal of Mathematics should be in typed form or offset-reproduced (not dittoed), double spaced with large margins. Underline Greek letters in red, German in green, and script in blue. The first paragraph or two must be capable of being used separately as a synopsis of the entire paper. Items of the bibliography should not be cited there unless absolutely necessary, in which case they must be identified by author and Journal, rather than by item number. Manuscripts, in duplicate, may be sent to any one of the four editors. Please classify according to the scheme of Math. Reviews, Index to Vol. 39. All other communications should be addressed to the managing editor, or Elaine Barth, University of California, Los Angeles, California, 90024.

100 reprints are provided free for each article, only if page charges have been substantially paid. Additional copies may be obtained at cost in multiples of 50.

The Pacific Journal of Mathematics is issued monthly as of January 1966. Regular subscription rate: $\$ 72.00$ a year (6 Vols., 12 issues). Special rate: $\$ 36.00$ a year to individual members of supporting institutions.

Subscriptions, orders for back numbers, and changes of address should be sent to Pacific Journal of Mathematics, 103 Highland Boulevard, Berkeley, California, 94708.

PUBLISHED BY PACIFIC JOURNAL OF MATHEMATICS, A NON-PROFIT CORPORATION Printed at Jerusalem Academic Press, POB 2390, Jerusalem, Israel.

\section{Copyright (C) 1975 Pacific Journal of Mathematics All Rights Reserved}




\section{Pacific Journal of Mathematics

Vol. 60, No. $2 \quad$ October, 1975

Waleed A. Al-Salam and A. Verma, A fractional Leibniz q-formula ........... 1

Robert A. Bekes, Algebraically irreducible representations of $L_{1}(G) \ldots \ldots \ldots \ldots 11$

Thomas Theodore Bowman, Construction functors for topological

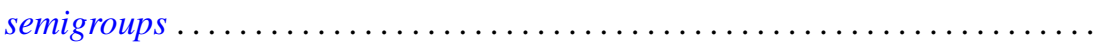

Stephen LaVern Campbell, Operator-valued inner functions analytic on the

closed disc. II .........................................

Leonard Eliezer Dor and Edward Wilfred Odell, Jr., Monotone bases in $L_{p} \ldots \ldots$.

Yukiyoshi Ebihara, Mitsuhiro Nakao and Tokumori Nanbu, On the existence of

global classical solution of initial-boundary value problem for

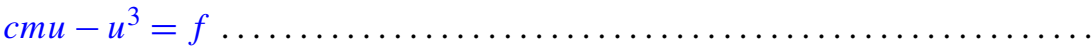

Y. Gordon, Unconditional Schauder decompositions of normed ideals of

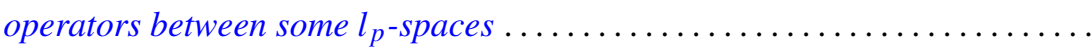

Gary Grefsrud, Oscillatory properties of solutions of certain nth order functional

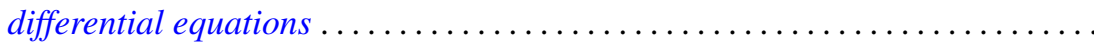

Irvin Roy Hentzel, Generalized right alternative rings ...................

Zensiro Goseki and Thomas Benny Rushing, Embeddings of shape classes of compacta in the trivial range .................................

Emil Grosswald, Brownian motion and sets of multiplicity . .

Donald LaTorre, A construction of the idempotent-separating congruences on a

bisimple orthodox semigroup .

Pjek-Hwee Lee, On subrings of rings with involution ...

Marvin David Marcus and H. Minc, On two theorems of Frobenius ...

Michael Douglas Miller, On the lattice of normal subgroups of a direct

product. .

Grattan Patrick Murphy, A metric basis characterization of Euclidean space

Roy Martin Rakestraw, A representation theorem for real convex functions ....

Louis Jackson Ratliff, Jr., On Rees localities and $H_{i}$-local rings ...

Simeon Reich, Fixed point iterations of nonexpansive mapping . .

Domenico Rosa, $B$-complete and $B_{r}$-complete topological algebras ...

Walter Roth, Uniform approximation by elements of a cone of real-valued

functions ....

Helmut R. Salzmann, Homogene kompakte projektive Ebenen

Jerrold Norman Siegel, On a space between $B H$ and $B_{\infty} \ldots$

235

Robert C. Sine, On local uniform mean convergence for Markov operators

James D. Stafney, Set approximation by lemniscates and the spectrum of an

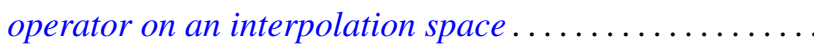

Árpád Száz, Convolution multipliers and distributions .......

Kalathoor Varadarajan, Span and stably trivial bundles ..........

Robert Breckenridge Warfield, Jr., Countably generated modules over

commutative Artinian rings....................... 